\title{
Severity and Outcomes in Association with Known Exposures and Susceptibilities among Afro-Caribbean Patients with Hospital-acquired Acute Kidney Injury
}

\author{
KK Hoe ${ }^{1,2,3}$, EN Barton ${ }^{1,2,3}$, TL Han ${ }^{1}$, TH Hoe ${ }^{1}$
}

\begin{abstract}
Objective: To investigate the severity and outcomes associated with known exposures and susceptibilities in Afro-Caribbean patients with hospital-acquired acute kidney injury (HA-AKI).

Methods: This was a single centre hospital-based cohort study. Acute kidney injury was diagnosed and staged by the criteria of Kidney Disease: Improving Global Outcomes.

Results: Among 107 Afro-Caribbean patients who were newly diagnosed with HA-AKI within a one-year period, hypertension (51.4\%) and diabetes mellitus (34.6\%) were the most common co-existing susceptibilities. None of the selected susceptibilities led to a higher demand for renal replacement therapy (RRT) or a higher risk of 90-day mortality, except in a small subgroup with underlying malignancy in which 12 out of 28 (42.9\%) demised at $\leq 90$ days after AKI (odds ratio (OR): 2.36; 95\% confidence interval (CI): 1.05, 5.87; $\mathrm{p}=0.05$ ). The risk for the requirement for dialysis was nine-fold higher if the patient had oliguria/anuria (OR: 9.06; 95\% CI: 3.06, 29.04; $\mathrm{p}$ 50.001). Oliguria/anuria was also found to be a major risk factor for 90-day mortality (OR: 4.46; 95\% CI: 1.83, 10.84; $\mathrm{p}<0.001$ ). Sepsis was the most frequent exposure (66\%) with a high chronic kidney disease conversion rate of 25.7\% (OR: 1.296; 95\% CI: 0.70, 2.38). Patients with HA-AKI and sepsis had a three-fold higher mortality among hospitalized patients with AKI (OR: 2.87; 95\% CI: 1.05, 7.87; $\mathrm{p}=0.03$ ). Both complicated non-cardiac major surgeries and cardiac surgeries were significantly associated with requirement for RRT (57.1\% versus $56.3 \%$ and $O R: 5.01 ; 95 \%$ CI: $1.04,24.1 ; \mathrm{p}=0.02$ versus $O R: 6.02 ; 95 \%$ CI: $1.95,18.57 ; \mathrm{p} \leq 0.001$, respectively). The requirement for $R R T$ in patients with HA-AKI was also significantly associated with admission to the intensive care unit (ICU) (42.1\%; OR: 4.6; 95\% CI: 1.54, 13.77; $\mathrm{p}=0.004$ ), systemic hypotension (OR: 5.86; 95\% CI: 2.07, 16.62; $\mathrm{p}=$ $0.001)$ and haemorrhagic shock (OR: 5.78; 95\% CI: 1.63, 20.51; $\mathrm{p}=0.003)$. The former two groups carried a significantly higher 90-day mortality rate (OR: 6.22; 95\% CI: 2.15, 17.99; $\mathrm{p}$ $\leq 0.001$ versus $O R: 5.54 ; 95 \%$ CI: $2.14,14.33 ; \mathrm{p} \leq 0.001$, respectively).

Conclusion: We observed that certain exposures (such as sepsis, oliguria, systemic hypotension, haemorrhagic shock, ICU admission and complicated major surgeries) had a significant influence on severity and adverse renal outcomes and this was independent of susceptibilities.
\end{abstract}

Keywords: Hospital-acquired acute kidney injury, ICU admission, oliguria, sepsis, shock

From: ${ }^{1}$ Division of Nephrology and Hypertension and Renal Transplantation, Department of Medicine, The University of the West Indies, Mona, Kingston, Jamaica, West Indies, ${ }^{2}$ University Hospital of the West Indies, Kingston, Jamaica, West Indies and ${ }^{3}$ Caribbean Institute of Nephrology, Kingston, Jamaica, West Indies.
Correspondence: Dr KK Hoe, Department of Medicine, University Hospital of the West Indies, Kingston 7, Jamaica, West Indies. Email: kk_hoe@hotmail.com 


\title{
Severidad y resultados clínicos asociados con exposiciones y susceptibilidades conocidas entre pacientes afrocaribeños con lesión renal aguda adquirida en el hospital
}

\author{
KK Hoe ${ }^{1,2,3}$, EN Barton ${ }^{1,2,3}$, TL Han ${ }^{1}$, TH Hoe ${ }^{1}$
}

\begin{abstract}
RESUMEN
Objetivo: Investigar la severidad y los resultados clínicos asociados con exposiciones y susceptibilidades conocidas en pacientes afrocaribeños con lesión renal aguda adquirida en el hospital (LRA-AH).

Métodos: Se trató de un estudio de cohorte basado en un solo centro hospitalario. La lesión renal aguda fue diagnosticada y estadificada según los criterios de la enfermedad renal: mejorar los resultados globales.

Resultados: Entre los 107 pacientes afrocaribeños que fueron diagnosticados recientemente con LRA-AH en el periodo de un año, la hipertensión (51.4\%) y la diabetes mellitus (34.6\%) fueron las susceptibilidades coexistentes más comunes. Ninguna de las susceptibilidades seleccionadas condujo a una mayor demanda de terapia de reemplazo renal (TRR) o a un mayor riesgo de mortalidad de 90 días, excepto en un pequeño subgrupo con malignidad subyacente en el que 12 de 28 (42.9\%) fallecen a $\leq 90$ días después de LRA (odds ratio (OR): 2.36; 95\% intervalo de confianza (CI): $1.05,5.87 ; \mathrm{p}=0.05)$. El riesgo de la necesidad de diálisis fue nueve veces mayor si el paciente tenía oliguria/anuria (OR: 9.06; 95\% IC: 3.06, 29.04; $\mathrm{p} \leq$ 0.001). También se descubrió que la oliguria/anuria era un factor de riesgo importante para la mortalidad en 90 días (OR: 4.46; 95\% IC: 1.83, 10.84; $\mathrm{p}<0.001)$. Sepsis fue la exposición más frecuente (66\%) con una tasa de conversión de la enfermedad renal crónica alta de $25.7 \%$ (OR: 1.296; 95\% IC: 0.70, 2.38). Los pacientes con LRA-AH y sepsis tuvieron una mortalidad tres veces mayor entre los pacientes hospitalizados con LRA (OR: 2.87; 95\% IC: 1.05, 7.87; $\mathrm{p}=0.03)$. Tanto las cirugías principales no cardíacas complicadas como las cirugías cardiacas se asociaron significativamente con la necesidad de TRR (57.1\% versus $56.3 \%$ y OR: 5.01; 95\% IC: 1.04, 24.1; $\mathrm{p}=0.02$ versus OR: 6.02; 95\% IC: 1.95, 18.57; $\mathrm{p} \leq 0.001$, respectivamente). La necesidad de TRR en pacientes con LRA-AH también se asoció signifcativamente con la admisión a la unidad de cuidados intensivos (UCI) (42.1\%; OR: 4.6; 95\% IC: $1.54,13.77 ; \mathrm{p}=0.004)$, hipotensión sistémica (OR: 5.86; 95\% IC: $2.07,16.62 ; \mathrm{p}=0.001)$ y choque hemorrágico (OR: 5.78; 95\% IC: 1.63, 20.51; $\mathrm{p}=0.003)$. Los dos grupos anteriores tuvieron una tasa de mortalidad de 90 dias significativamente mayor (OR: 6.22; 95\% IC: 2.15 , 17.99; $\mathrm{p} \leq 0.001$ versus OR: 5.54; 95\% IC: 2.14, 14.33; $\mathrm{p} \leq 0.001$, respectivamente).

Conclusión: Observamos que ciertas exposiciones (tales como sepsis, oliguria, hipotensión sistémica, shock hemorrágico, admisión en la UCI, y cirugías principales complicadas) tuvieron una influencia significativa en la severidad y los resultados clínicos renales adversos, con independencia de las susceptibilidades.
\end{abstract}

Palabras clave: Lesión renal aguda adquirida en el hospital, admisión en la UCI, oliguria, sepsis, shock

West Indian Med J 2019; 68 (1): 36

\section{INTRODUCTION}

Among the 1.7 million estimated global deaths from acute kidney injury (AKI) per year, $82 \%$ (1.4 million) of deaths occur in the low-/middle-income countries
(1). The risk factors associated with AKI, its severity and outcomes vary with different geographic regions. The overall incidence of AKI among the hospitalized patients was estimated to be between $5 \%$ and $7 \%$ 
of the total admission (2). A study in Spain concluded that the most common cause of hospital-acquired acute kidney injury (HA-AKI) was acute tubular necrosis (ATN) $(45 \%)$, followed by pre-renal (21\%), post-renal $(10 \%)$, renal vascular disorder (3\%), glomerulonephritis $(3 \%)$ and acute interstitial nephritis $(2 \%)$. That group also demonstrated that $27 \%$ of HA-AKI occurred in the intensive care unit (ICU) (3). Another HA-AKI study from France, based on ICU cases, reported that $78 \%$ of AKI was due to ATN, $17 \%$ was pre-renal and only $5 \%$ was post-renal (4). There is an increasing need to recognize and understand modifiable risk factors as a key to prevent AKI, with many articles focussed on certain modifiable risk factors which included dehydration, hypovolaemia, nephrotoxic medications or contrast agents, surgery-related issues, sepsis and the cardiorenal syndrome (5-7). The recognized predictors of mortality were stated as oliguria, sepsis, bleeding, length of ICU stay, requirement for ventilator, and multi-organ failure. In the HA-AKI group, the mortality was higher among elderly patients (8). Koulouridis et al reported that the chance of hospital readmission was higher among the HA-AKI survivors than other discharged patients (9). Alexandra et al highlighted the effect of old age on renal outcomes. Their findings concluded that the risk of occurrence of AKI was high among the hospitalized elderly patients and it also led to a higher mortality and the development or worsening of chronic kidney disease (CKD) (10). To find out the influence of selected exposures and susceptibilities on severity and adverse renal outcomes such as the rate of CKD conversion, requirement for renal replacement therapy (RRT) and 90-day mortality, we conducted this institution-based study among the hospitalized patients, who were all Afro-Caribbean.

\section{Defining exposures and susceptibilities for acute kidney injury}

The guidelines of Kidney Disease: Improving Global Outcomes (KDIGO) suggested stratification of the risk of AKI according to its susceptibilities and exposures. Individual susceptibility to developing AKI after exposure to a similar insult is quite different from person to person. Based on multiple studies, the KDIGO group set exposures as sepsis, critical illness, circulatory shock, burns, trauma, cardiac surgery (especially with cardiopulmonary bypass), major non-cardiac surgery, nephrotoxic drugs, radiocontrast agents, and poisonous plants, but AKI was found more in the susceptible group that includes patients with dehydration or volume depletion, advanced age, female gender, Black race, CKD, chronic diseases (heart, lung, liver), diabetes mellitus, cancer, and anaemia (11) (Table 1).

\section{Defining and staging acute kidney disease}

In 2003, the Risk, Injury, Fail, Loss and End stage (RIFLE) criteria graded AKI based on changes in serum creatinine ( $\mathrm{SCr}$ ) or urine output. The RIFLE criteria were widely used to conduct many studies on AKI (12-17).

However, further studies from 2004 onwards demonstrated that a change in $\mathrm{SCr}$ of as little as $0.3 \mathrm{mg} / \mathrm{dL}$ $(26.5 \mu \mathrm{mol} / \mathrm{L})$ was associated with a significant rise in mortality among hospitalized patients (18). Lassnigg et al found that patients undergoing cardiac surgery who sustained postoperative absolute small $\mathrm{SCr}$ increases over the first 48 hours (defined by an increase of up to $0.5 \mathrm{mg} / \mathrm{dL}$ ) had an increased 30-day mortality risk (19). Subsequently, in 2007, the new definition was set by the Acute Kidney Network group (AKIN) which defined AKI as an abrupt (within 48 hours) reduction in kidney function with rise in absolute $\mathrm{SCr}$, a percentage increase in $\mathrm{SCr}$ level and a reduction in urine output (20). The importance of nadir to peak $\mathrm{SCr}$ was further highlighted by Broce et al in 2011 when they found that a $\mathrm{SCr}$ increase of $\geq 0.2 \mathrm{mg} / \mathrm{dL}, \geq 0.3 \mathrm{mg} / \mathrm{dL}$ and $\geq 0.5 \mathrm{mg} /$ $\mathrm{dL}$ among patients with a baseline estimated glomerular filtration rate of $\geq 60,30-59$ and $<30 \mathrm{ml} /$ minute $/ 1.73$ $\mathrm{m}^{2}$, respectively, was independently associated with inhospital mortality (21).

In 2012, in the KDIGO guidelines, AKI was defined by an increase in SCr by $0.3 \mathrm{mg} / \mathrm{dL}(26.5 \mu \mathrm{mol} / \mathrm{L})$ within 48 hours; or an increase in SCr to 1.5 times baseline, which is known or presumed to have occurred within the

Table 1: Exposures and susceptibilities for non-specific acute kidney injury

\begin{tabular}{ll}
\hline Exposures & Susceptibilities \\
\hline Sepsis & Dehydration or volume depletion \\
Critical illness & Advanced age \\
Circulatory shock & Female gender \\
Burns & Black race \\
Trauma & Chronic kidney disesase \\
Cardiac surgery & Chronic diseases (heart, lung, liver) \\
Major non-cardiac surgery & Diabetes mellitus \\
Nephrotoxic drugs & Cancer \\
Radiocontrast agents & Anaemia \\
Poisonous plants and animals & \\
Cardiopulmonary bypass & \\
Being hospitalized, especially for & \\
a serious condition that requires & \\
intensive care & \\
Peripheral artery disease & \\
\hline
\end{tabular}


prior seven days; or a urine volume of $<0.5 \mathrm{ml} / \mathrm{kg} / \mathrm{hour}$ for six hours (11).

\section{SUBJECTS AND METHODS}

A cohort study was conducted to identify the cases of HA-AKI among the hospitalized patients at the University Hospital of the West Indies (UHWI), Jamaica, from July 2016 to June 2017. Ethical approval for the study was granted by the Ethics Committee of the Faculty of Medical Sciences, The University of the West Indies, Mona, Jamaica. Inclusion criteria were: patients with rising $\mathrm{SCr}$ more than 1.5 times from the baseline in the past seven days, absolute $\mathrm{SCr}$ rise of $>26.3 \mu \mathrm{mol} / \mathrm{L}$ in the past 48 hours, and urine output of $<0.5 \mathrm{ml} / \mathrm{kg} /$ hour for over six hours. All patient-data were coded and kept anonymous.

\section{Data collection}

The parameters were collected by trained recruiters (which included research nurses and graduate students) from each patient-record after the diagnosis of HA-AKI by certified nephrologists. These parameters were the patient's age, gender, baseline $\mathrm{SCr}$, the peak $\mathrm{SCr}, \mathrm{SCr}$ at $\geq 90$ days, duration of $\mathrm{AKI}$, requirement for dialysis, and 90-day mortality. The recruiters also collected independent variables which involved background medical illnesses, ICU admission, history of recent major surgery, hypotension, massive blood loss, use of nephrotoxic agents and radiocontrast agents, sepsis, and oliguria. To reduce the number of variables, we excluded some uncommon exposures (such as burns, animal and plant poison, and peripheral arterial disease) and some susceptible factors (such as chronic liver and lung disease). Clinical data were reviewed at subsequent follow-up visits and at $\geq 90$ days for the occurrence of CKD and/or end stage renal disease (ESRD).

\section{Statistical analysis}

Patients' demographic characteristics and clinical outcomes as continuous numerical variables are expressed as counts and percentages or mean with standard deviations (SD). The Pearson Chi-square $\left(\mathrm{X}^{2}\right)$ test was used to compare the proportion of different outcomes among different stages of HA-AKI. Both Pearson Chi-square and Phi tests were applied to compare the correlation, level of association and odds ratio (OR) among the exposures, susceptibilities and severity staging of HA-AKI and variable outcomes. Normally distributed data were expressed as mean $\pm \mathrm{SD}$. A $p$-value of $<0.05$ was considered statistically significant. The data of correlation between sample populations were applied by means of $95 \%$ confidence interval (CI). All statistical analysis was done by using IBM SPSS version 22.

\section{RESULTS}

A total of 107 patients met the criteria for HA-AKI. The mean age $\pm \mathrm{SD}$ of the patients with HA-AKI was 65.92 \pm 19.6 years. In the full cohort, $34.6 \%$ had stage $1 \mathrm{AKI}$, $20.6 \%$ had stage 2 AKI and $44.9 \%$ had stage 3 AKI. In these patients with HA-AKI, 43 (40.19\%) were males, and $64(59.81 \%)$ were females. The mean $\mathrm{SCr}$ at presentation was $131 \pm 31.4 \mu \mathrm{mol} / \mathrm{L}, 216 \pm 30.7 \mu \mathrm{mol} / \mathrm{L}$ and $593 \pm 133 \mu \mathrm{mol} / \mathrm{L}$ for stages 1,2 and 3, respectively. The proportion of AKI patients with underlying susceptible factors is collectively shown in Table 2. Among these Afro-Caribbean HA-AKI patients with known susceptibilities, hypertension (51.4\%) and diabetes $(34.6 \%)$ were found as two leading vulnerable factors. Underlying CKD was found in $27.4 \%$ of this study group with respect to other susceptibilities, anaemia was detected in $30.2 \%$, and co-existing cancer was observed in $26.4 \%$. History of recent cardiac surgery, non-cardiac major surgery and cardiac failure was noted in $15.1 \%$, $6.6 \%$ and $18.9 \%$ of patients with HA-AKI, respectively.

\section{Overall renal outcomes}

Of the 107 patients, 90-day mortality was observed in 31 (29\%) patients in whom $61.2 \%$ had stage 3 AKI, $29 \%$ had stage 2 AKI and 9.6\% had stage 1 AKI. The rate of incomplete renal recovery at $\geq 90$ days was $28 \%$ in which $53.3 \%$ had stage 3 AKI, 16\% had stage 2 AKI and $30 \%$ had stage 1 AKI. Overall, 20 patients (18.7\%) required RRT. Of the dialysed group, $85 \%$ were diagnosed as having stage $3 \mathrm{AKI}$ and $15 \%$ as having stage 2 AKI. Among the surviving patients, ESRD was declared at $\geq 90$ days for three patients $(2.8 \%)$ (Table 2$)$.

\section{Gender and the risk of renal outcomes}

Among male and female patients, females had a higher rate of CKD progression (30.2\% versus $25.6 \%)$ and $\geq$ 90 -day mortality $(31.3 \%$ versus $25.6 \%)$. The requirement for dialysis was higher among the male patients with HA-AKI (20.9\% versus $17.2 \%)$. Patients with HA-AKI in this study were solely of Afro-Caribbean descent.

\section{Aetiological assessment of acute kidney injury}

In this study, $52.34 \%$ of HA-AKI was secondary to toxic/ischaemic ATN (Fig. 1). We also observed that a significant number of patients had combined aetiologies 
Table 2: Baseline characteristics, susceptibilities, severity and outcomes of the patients with hospital-acquired acute kidney injury (n (\%))

\begin{tabular}{|c|c|c|c|c|}
\hline & $\begin{array}{c}\text { Stage } 1 \text { acute kidney } \\
\text { injury }(\mathrm{AKI})\end{array}$ & Stage 2 AKI & Stage 3 AKI & Total \\
\hline \multicolumn{5}{|l|}{$\underline{\text { Characteristics }}$} \\
\hline $\mathrm{n}(\%)$ & $37(34.6)$ & $22(20.6)$ & $48(44.9)$ & $107(100)$ \\
\hline Age (years \pm standard deviation) & $65.7 \pm 20.47$ & $69.0 \pm 16.55$ & $64.67 \pm 20.5$ & $65.92 \pm 19.6(17100)$ \\
\hline \multicolumn{5}{|l|}{ Gender } \\
\hline Male & $20(46.5)$ & $8(18.6)$ & $15(34.9)$ & $43(40.19)$ \\
\hline Female & $17(26.6)$ & $14(21.9)$ & $33(51.6)$ & $64(59.81)$ \\
\hline \multicolumn{5}{|l|}{$\underline{\text { Susceptibilities }}$} \\
\hline Diabetes & $14(13.1)$ & $9(8.4)$ & $14(13.1)$ & $37(34.5)$ \\
\hline Hypertension & $22(20.6)$ & $13(12.1)$ & $20(18.7)$ & $55(51.4)$ \\
\hline Chronic kidney disease & $15(14.0)$ & $6(5.6)$ & $8(7.5)$ & $29(27.4)$ \\
\hline Cardiac failure & $8(7.5)$ & $6(5.6)$ & $6(5.6)$ & $20(18.9)$ \\
\hline Anaemia & $12(11.2)$ & $5(4.7)$ & $15(14.0)$ & $32(30.2)$ \\
\hline Cancer & $9(8.4)$ & $5(4.7)$ & $14(13.1)$ & $28(26.4)$ \\
\hline Non-cardiac major surgery & $1(0.9)$ & $1(0.9)$ & $5(4.7)$ & $7(6.6)$ \\
\hline Cardiac surgery & $3(2.8)$ & $2(1.9)$ & $11(10.3)$ & $16(15.1)$ \\
\hline \multicolumn{5}{|l|}{$\underline{\text { Renal outcomes }}$} \\
\hline $\begin{array}{l}\text { Incomplete recovery (chronic kidney } \\
\text { disease) }\end{array}$ & $9(24.3)$ & $5(22.7)$ & $16(33.3)$ & $30(28)$ \\
\hline Proceed to end stage renal disease & $0(0)$ & $0(0)$ & $3(2.8)$ & $3(2.8)$ \\
\hline Requirement for dialysis & $0(0)$ & $3(2.8)$ & $17(15.9)$ & $20(18.7)$ \\
\hline 90-day mortality & $3(2.8)$ & $9(8.4)$ & $19(17.8)$ & $31(29)$ \\
\hline
\end{tabular}

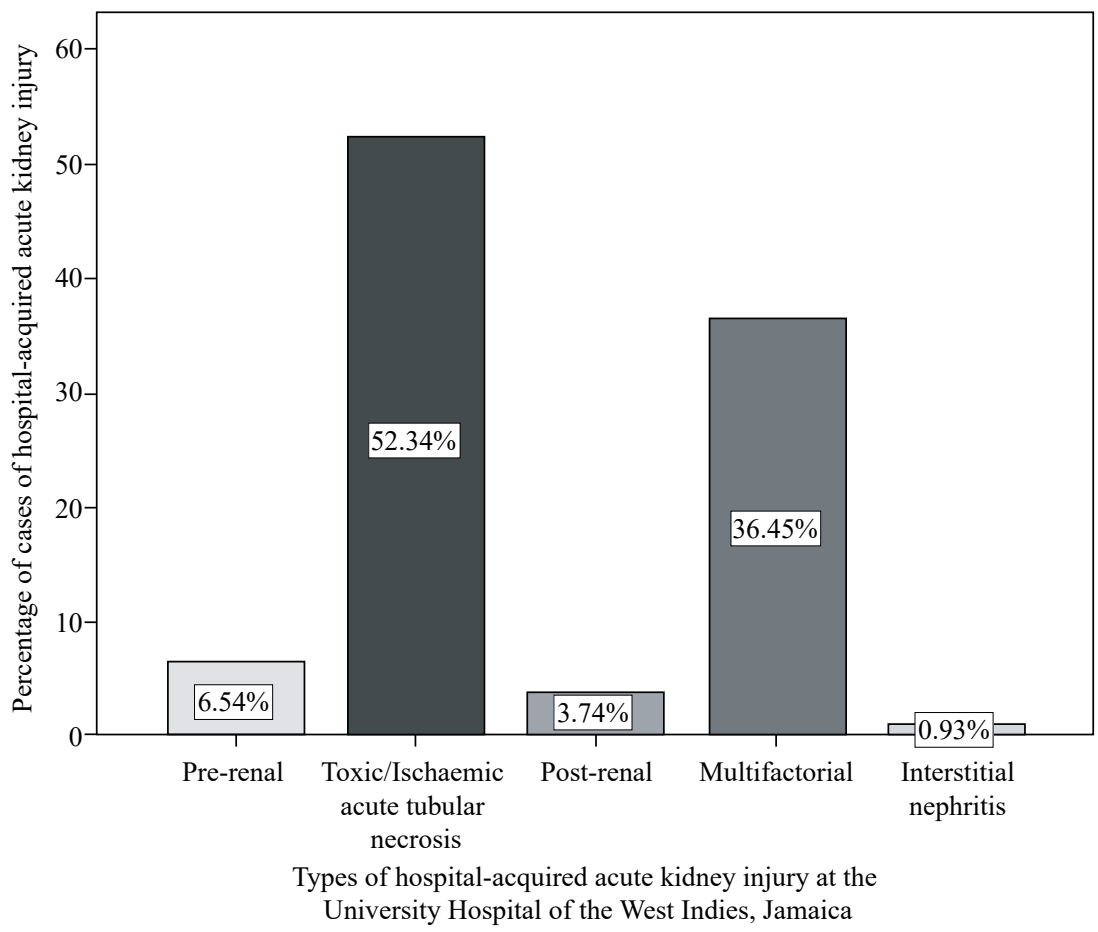

Fig. 1: Causes of hospital-acquired acute kidney injury in the studied Afro-Caribbean population. 
of pre-renal, intrinsic renal and post-renal conditions $(36.45 \%)$. Pure pre-renal type of AKI was found in $6.54 \%$ of the studied population, and post-renal AKI represented only $3.74 \%$ of HA-AKI. Histologically proven acute interstitial nephritis was noted in only one patient $(0.93 \%)$.

\section{Frequencies of individual susceptibilities}

Various susceptibilities are shown in Table 3. Underlying diabetes, hypertension, $\mathrm{CKD}$, cardiac failure, anaemia and cancer were found in $34.7 \%(\mathrm{n}=37), 50.9 \%(\mathrm{n}=$ $54), 27.4 \%(\mathrm{n}=29), 18.9 \%(\mathrm{n}=20), 30.2 \%(\mathrm{n}=32)$ and $26.4 \%(n=28)$ of the study group, respectively. Hence, hypertension followed by diabetes was the most prevalent underlying vulnerable factor in this Afro-Caribbean HA-AKI study group.

\section{The development of chronic kidney disease based on susceptibilities}

Underlying hypertension was observed in 55 patients (51.4\%) among those with HA-AKI. The incidence rate of CKD among these patients with hypertension was $13.0 \%(\mathrm{n}=14)$, but it was not statistically significant (OR: 0.78; 95\% CI: 0.33, $1.83 ; p=0.58$ ). Similarly, 13 out of 37 patients (12.1\%) with underlying diabetes, 6 out of $20(5.7 \%)$ with cardiac failure and 8 out of 32 (7.5\%) with anaemia proceeded to CKD after HA-AKI but statistically, none of these showed a statistically significant correlation (OR: 1.76; 95\% CI: $0.73,4.21 ; p=$ 0.14; OR: 1.1 ; 95\% CI: $0.38,3.21 ; p=0.85$; and OR: 0.78 ; 95\% CI: $0.3,2.02 ; p=0.42$, respectively). Of 28 patients with underlying malignancy, only three $(2.8 \%)$ did not get back their baseline renal function at $\geq 90$ days after HA-AKI, and this was found to be negatively associated with the incidence of CKD (OR: $0.22 ; 95 \%$ CI: $0.06,0.81 ; p=0.01)$ as that particular group had a very high 90 -day mortality rate (Fig. 2).

\section{Requirement for renal replacement therapy based on susceptibilities}

Figure 2 also describes the requirement for RRT in HA-AKI patients with associated vulnerable factors. None of the selected susceptibilities was likely to cause the requirement for RRT. Patients with diabetes, hypertension, $\mathrm{CKD}$, cardiac failure, anaemia and malignancy shared almost equal hazard ratios to that of the normal population for the requirement for RRT. No statistical significance was found among any of the selected susceptibilities and RRT requirement ( $p$-value of all $\geq 0.05$ ).

\section{Ninety-day mortality outcomes based on different susceptibilities}

Table 3 shows the 90-day mortality outcome of patients with HA-AKI based on selected underlying susceptibilities. A subgroup analysis of each vulnerable factor for 90-day mortality rate was performed. This analysis revealed a rather similar result as requirement for RRT, indicating that individual selected susceptibilities did not have a statistically significantly higher risk of 90-day mortality outcome, except in the subgroup with underlying malignancy in which 12 out of 28 died (42.9\%) at $\leq$ 90 days after AKI, and it was associated with two-fold higher rate of 90 -day mortality (OR: 2.36 ; $95 \%$ CI: 1.05 , $5.87 ; p=0.05)$.

\section{Frequencies of exposures and the development of chronic kidney disease after exposures}

During the study period, 70 out of 107 patients with HA-AKI (66\%) had sepsis which was the leading risk factor among the exposures. Of these patients who were labelled as having sepsis, $25.7 \%$ were found to have incomplete renal recovery at $\geq 90$ days, and they were recognized as having CKD after AKI (OR: 1.296; 95\% CI: $0.70,2.38$ ). Oliguria/anuria was documented in 36 (34\%) of patients with HA-AKI, among which eight (22\%) progressed to CKD (OR: $1.41 ; 95 \%$ CI: 0.71, 2.85). Sixteen patients (15.1\%) developed AKI after cardiac surgery, and seven (6.6\%) had AKI after noncardiac major surgery. Progression to CKD was reported in four patients $(25 \%)$ among the cardiac surgery group (OR: $1.15 ; 95 \%$ CI: $0.46,2.85)$ and two $(28.6 \%)$ in the non-cardiac major surgery group (OR: $1.01 ; 95 \% \mathrm{CI}$ : $0.61,1.63)$. Documented hypotension was observed in $26(24.6 \%)$ of the patients with HA-AKI, and two (19.2\%) remained with CKD (OR: 1.65 ; 95\% CI: 0.68, 3.99). History of haemorrhagic shock was documented in $12(11.3 \%)$, and only two $(10.5 \%)$ of them developed CKD (OR: 1.78; 95\% CI: 0.48, 6.57). Admission to ICU was reported in $19(17.9 \%)$ of the patients with HA-AKI, and this was associated with a three-fold rise in the development of CKD (OR: 3.05; 95\% CI: 0.79, 11.76; $p=0.058$ ) (Table 4).

Requirement for dialysis after individual exposures among patients with hospital-acquired acute kidney injury

Table 4 also includes the outcomes of RRT requirement in patients with HA-AKI based on individual exposure. Fifteen out of 36 HA-AKI patients (41.7\%) with oliguria/anuria received dialysis, and the risk for the 


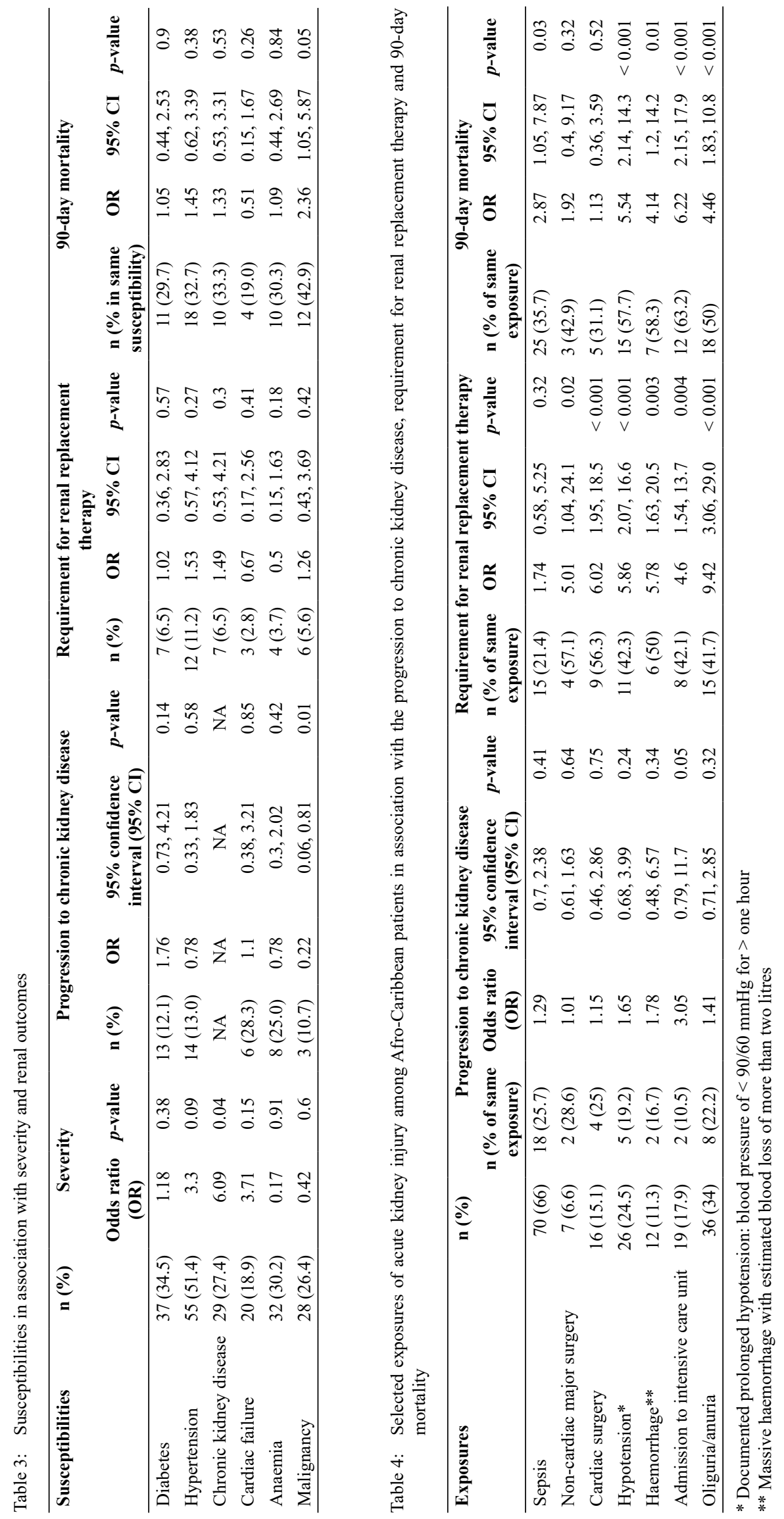


60

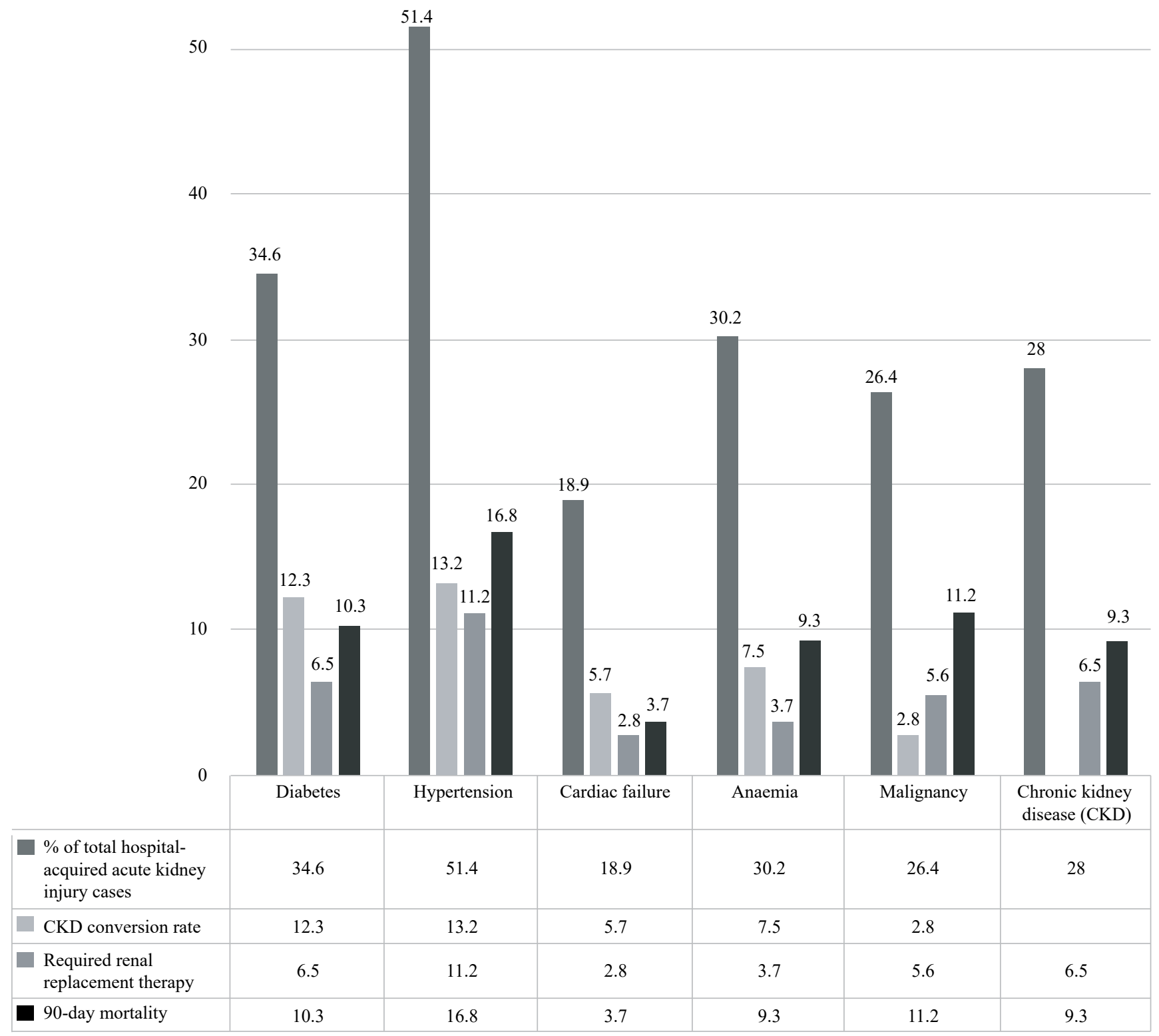

Fig. 2: Susceptibilities and renal outcomes in patients with hospital-acquired acute kidney injury $(\mathrm{n}=107)$. Susceptibilities such as diabetes, hypertension, cardiac failure, anaemia and malignancy were not significantly associated with chronic kidney disease conversion and the requirement for renal replacement therapy.

requirement for dialysis was as high as nine-fold $(95 \%$ CI: 3.06, 29.04; $p \leq 0.001)$. Although non-cardiac major surgery was much less prevalent in the study group, four out of seven of these patients with HA-AKI (57.1\%) required dialysis after complicated major surgeries (OR: 5.01; 95\% CI: 1.04, 24.1; $p=0.02$ ), and it was recognized as the leading exposure for the requirement for dialysis in this study. However, among the patients who developed AKI after major cardiac surgery, 9 out of $16(56.3 \%)$ required dialysis. Cardiac surgery had a six-fold increase in risk for dialysis requirement, and this was also statistically significant (OR: 6.02; 95\% CI: $1.95,18.57 ; p=0.001)$. Six out of 12 patients with documented haemorrhagic shock needed dialysis after the diagnosis of AKI (OR: 5.78; 95\% CI: 1.63, 20.51; $p=$ $0.003)$. Fifteen patients who had sepsis and AKI (21.4\%) needed dialysis, and sepsis alone did not statistically significantly contribute to the requirement for dialysis (OR: 
1.71; 95\% CI: $0.58,5.25 ; p=0.32$ ). Among the patients with documented hypotension and AKI, 11 (42.3\%) received dialysis (OR: 5.86; 95\% CI: 2.07, 16.62; $p=$ 0.001). Of 19 HA-AKI patients with ICU admission, eight $(42.1 \%)$ required dialysis (OR: 4.6 ; 95\% CI: 1.54 , $13.77 ; p=0.004)$.

\section{Exposures and 90-day mortality in patients with hospital-acquired acute kidney injury}

There was high mortality among patients diagnosed with HA-AKI during the one-year study period. Patients with stage 3 AKI had the highest mortality rate (17.8\%), followed by stage 2 AKI (8.4\%) and stage 1 AKI (2.8\%). The risk of mortality was highest up to five-fold and six-fold, respectively, in HA-AKI patients with systemic hypotension (OR: $5.54 ; 95 \%$ CI: $0.14,14.33 ; p<0.001$ ) and ICU admission (OR: 6.22; 95\% CI: 2.15, 17.99; $p \leq$ $0.001)$. Overall mortality among HA-AKI patients with systemic hypotension was $57.7 \%$ and among HA-AKI patients with ICU admission was $63.2 \%$. Twenty-five (35.7\%) out of 70 HA-AKI patients with sepsis died at $\leq$ 90 days after the diagnosis of AKI. Sepsis increased the risk of mortality in the hospitalized patients up to threefold (OR: 2.87; 95\% CI: 1.05, 7.87; $p=0.03$ ). Patients who had haemorrhagic shock had an overall mortality rate of $58.3 \%$. The risk of mortality was also significantly high, up to four-fold in this group (OR: 4.14; 95\% CI: $1.2,14.27 ; p=0.007)$. Documented oliguria among HA-AKI patients also increased the risk of mortality significantly, and the mortality rate in these patients with prolonged oliguria was 50\% (OR: 4.46; $95 \% \mathrm{CI}: 1.83$, 10.84; $p=0.001$ ).

Of the 16 post-cardiac surgery patients, five (31.1\%) died at $\leq 90$ days after AKI, and among seven post-noncardiac major surgery patients, three demised (42.9\%). Although more cardiac surgery patients had higher frequency of AKI, both groups did not significantly increase the risk of 90-day mortality (OR: $1.13 ; 95 \% \mathrm{CI}$ : $0.36,3.59 ; p=0.52$ and OR: 1.92 ; 95\% CI: 0.4, 9.17; $p=0.4$, respectively) (Table 4, Fig. 3).

\section{DISCUSSION}

In this institution-based cohort study of patients who developed AKI after hospitalization, the overall 90-day mortality was $29 \%$, in which $61.2 \%$ had stage 3 AKI at the time of diagnosis. Hospital-acquired AKI has been a well-recognized leading cause of hospital death, and its mortality rate was as high as $68.1 \%$ in one of the studies conducted in Wales (22). Some previous studies have shown that the majority of the critically ill patients

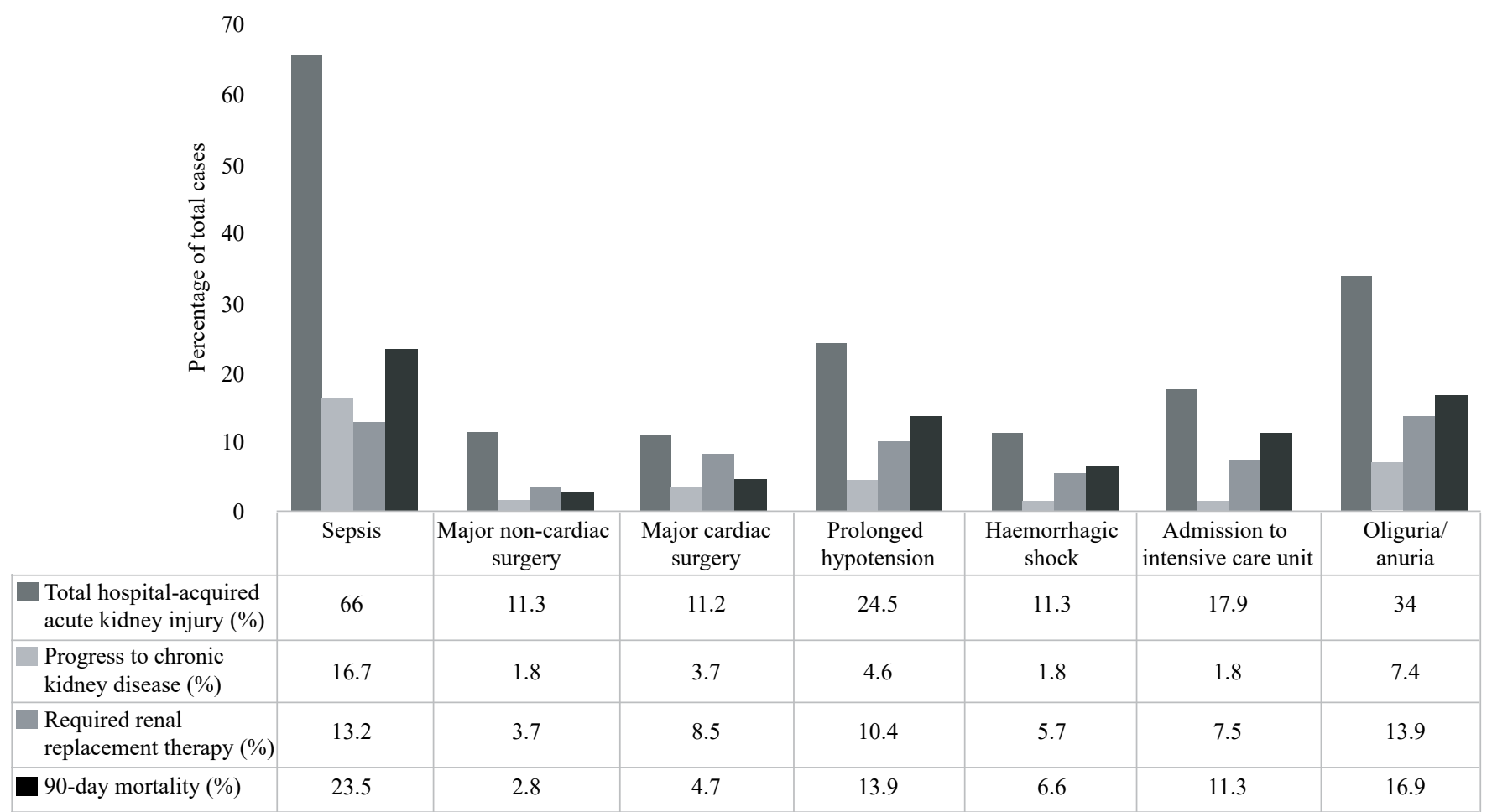

Fig. 3: Exposures and outcomes of hospital-acquired acute kidney injury at the University Hospital of the West Indies, Jamaica. Certain exposures such as sepsis, prolonged hypotension, haemorrhagic shock, admission to intensive care unit, oliguria/anuria had significant correlation with adverse renal outcomes of the requirement for renal replacement therapy and 90-day mortality. 
with HA-AKI usually die (23). A higher increase in $\mathrm{SCr}(3 \mathrm{mg} / \mathrm{dL})$ was a marker of higher mortality (24). Obialo et al found that the pre-renal cause of AKI was more common in the HA-AKI group when intrinsic renal injury was more common in the HA-AKI group and the latter carries higher mortality (25). In our study, although ATN remained as the most common cause of HA-AKI (53.27\%), the incidence of combined aetiology was significantly high $(36.45 \%)$, and it highlighted that a significant number of patients had complicated mixed pattern AKI beyond the straight-forward ATN.

We were able to demonstrate that the risk of mortality was significantly high in individual patients with any of the known exposures, namely, sepsis, oliguria/ anuria, systemic hypotension, haemorrhagic shock, complicated surgeries (both cardiac and non-cardiac) and ICU admission. Patients with ICU admission led with $63.2 \%$ of mortality which again confirmed that critical illness in combination with AKI was an independent risk factor for poor prognosis. Other exposures were also significantly associated with high mortality among patients with HA-AKI. These findings highlighted that exposures are the predictors of mortality and prevention of individual exposures may lead to significant reduction of AKI-associated mortality in the hospitalized patients. The higher rate of mortality among patients with HA-AKI might have been compounded by age factor in our study population as the average age of the patients in this study was 65.92 years. Surprisingly, no significant association was found between selected susceptibilities (such as diabetes, hypertension, CKD, cardiac failure, anaemia, female gender) and 90-day mortality. The significantly high mortality was observed in HA-AKI patients with underlying malignancy, but the contribution of AKI to mortality in this setting was not so clear.

Previous data demonstrated a 28 -fold increase in future development of CKD stage 4 or 5 and a two-fold increase in future mortality if these patients required dialysis (26). We noted that CKD conversion rate among this group of Afro-Caribbean patients was $28 \%$ and the majority of them had stage $3 \mathrm{AKI}$ at the time of diagnosis. Sub-analysis of the link between individual susceptibilities and CKD conversion showed no statistical significance. Similarly, the association between individual exposures and CKD conversion was statistically insignificant in our analysis. Therefore, the conversion to CKD after AKI cannot be predicted solely by individual exposures or susceptibilities. Larger studies may need to clarify this.
Hsu et al concluded that CKD was an independent risk factor for AKI in their findings which demonstrated that the hospitalized patients with CKD stage 3 or above had a higher incidence of AKI (27). Based on our study which was of an Afro-Caribbean population, $18.9 \%$ of patients with HA-AKI were found to have underlying CKD. Stewart et al expressed their frustration in a study which showed that the delayed recognition of the development of AKI was found to be as high as $43 \%$ after admission and one-fifth of these developments were believed to be avoidable (28). Data from the developed countries showed that sepsis was the leading cause of AKI. Fifty-one per cent of patients with septic shock were found to have AKI, and their prognosis was worse than those without AKI (29-31).

In an early study, iatrogenic factors accounted for $55 \%$ of HA-AKI (29). There is a large number of known nephrotoxins which have different and complex mechanisms to trigger different kinds of renal injuries $(32,33)$. We conducted data collection on exposure to known nephrotoxic agents as well, and a detailed analysis is under progress. In terms of RRT requirement, there was no association between the need for dialysis and any of the selected underlying susceptibilities including CKD. It indicated that the presence of background CKD may not have any influence on the decision to initiate RRT when these patients with background CKD developed HA-AKI.

However, the predictor of the RRT requirement was significantly linked with selected exposures. We were able to demonstrate significantly higher requirement for RRT in patients with oliguria/anuria, complicated surgeries (both cardiac and non-cardiac), haemorrhagic shock, systemic hypotension and ICU admission. Once the exposures (not susceptibilities in general) were found to be the predictors of adverse renal outcomes, focussing on the prevention of such exposures in hospitalized patients (whether they have any susceptibilities or not) would be a key factor to minimize adverse renal outcomes after AKI.

\section{LIMITATIONS}

This study has some limitations. Although we included all patients with HA-AKI admitted to the UHWI during the specific time frame, it does not reflect the entire population of the region, particularly those institutions without a dialysis facility and ICU service. It is highly possible that negative renal outcomes and mortality may be much higher in these areas where there is no dialysis facility and intensive care. All our patients were 
Afro-Caribbean, and this has been well recognized as one of the susceptibilities for AKI. The geographical variation in the susceptibilities may cause different adverse renal outcomes after HA-AKI. Insignificant influence of individual susceptibilities on the severity and adverse renal outcomes in this study might be related to the limited sample size. It may become statistically significant when the size of HA-AKI population becomes larger. We are continuing to collect data for newer patients with HA-AKI to strengthen our findings.

In addition, the study did not address the combined effect of two or more exposures or susceptibilities on the outcomes in any one patient. Some of the patients with initial stages 1 and 2 AKI continued to have rapid decline of renal function over a week with complete anuria but were graded according to their initial findings, even though a few of them became stage 3 AKI. Finally, the decision to initiate RRT was the personal decision of the nephrologists involved in this study. There are no universally accepted guidelines on when to start dialysis in patients with AKI. Therefore, the validity of the association between the requirement for RRT and certain exposures (such as oliguria) is doubtful.

\section{ACKNOWLEDGEMENTS}

The authors thank the study participants, project staff and postgraduate and undergraduate medical students in the nephrology rotation at the UHWI for their contribution to the project.

\section{AUTHOR CONTRIBUTIONS}

KK Hoe conducted the study design, oversaw data collection, carried out data analysis, wrote the manuscript and edited its final version. EN Barton participated in data interpretation, critically revised the manuscript and approved its final version. TL Han and TH Hoe participated in the study design and graphical interpretation of data, revised the manuscript and approved its final version. The authors declare no conflicts of interest.

\section{REFERENCES}

1. Mehta RL, Cerdá J, Burdmann EA, Tonelli M, Garcia-Garcia G, Jha V et al. International Society of Nephrology's 0by 25 initiative for acute kidney injury (zero preventable deaths by 2025): a human rights case for nephrology. Lancet 2015; 385: 2616-43.

2. Ali T, Khan I, Simpson W, Prescott G, Townend J, Smith W et al. Incidence and outcomes in acute kidney injury: a comprehensive population-based study. J Am Soc Nephrol 2007; 18: 1292-8.

3. Liano F, Pascual I. Epidemiology of acute renal failure: a prospective, multicenter, community-based study. Kidney Int 1996; 50: 811-8.

4. Brivet FG, Kleinknecht DI, Loirat P, Landais P. Acute renal failure in intensive care units - causes, outcome and prognostic factors of hospital mortality: a prospective, multicenter study. Crit Care Med 1996; 24: 192-8.

5. Nash K, Hafeez A, Hou S. Hospital-acquired renal insufficiency. Am J Kidney Dis 2002; 39: 930-6.

6. Kohli HS, Bhaskaran MC, Muthukumar T, Thennarasu K, Sud K, Jha V. Treatment-related acute renal failure in the elderly: a hospital-based prospective study. Nephrol Dial Transplant 2000; 15: 212-7.

7. Baraldi $\mathrm{A}$, Ballestri $\mathrm{M}$, Rapanà $\mathrm{R}$, Lucchi $\mathrm{L}$, Borella $\mathrm{P}$, Leonelli $\mathrm{M}$ et al. Acute renal failure of medical type in an elderly population. Nephrol Dial Transplant 1998; 13 (Suppl 7): 25-9.

8. Kohli HS, Bhat A, Jairam A, Aravindan AN, Sud K, Jha V et al. Predictors of mortality in acute renal failure in a developing country: a prospective study. Ren Fail 2007; 29: 463-9.

9. Koulouridis I, Price LL, Madias NE, Jaber BL. Hospital-acquired acute kidney injury and hospital readmission: a cohort study. Am J Kidney Dis 2015; 65: 275-82.

10. Chronopoulos A, Cruz DN, Ronco C. Hospital-acquired acute kidney injury in the elderly. Nat Rev Nephrol 2010; 6: 141-9.

11. Kellum A, Lameire N. Diagnosis, evaluation, and management of acute kidney injury: a KDIGO summary (Part 1). Crit Care 2013; 17: 204.

12. Bagshaw SM, George C, Dinu I, Bellomo R. A multi-centre evaluation of the RIFLE criteria for early acute kidney injury in critically ill patients. Nephrol Dial Transplant 2008; 23: 1203-10.

13. Kellum JA, Bellomo R, Ronco C. Classification of acute kidney injury using RIFLE: what's the purpose? Crit Care Med 2007; 35: 1983-4.

14. Ricci Z, Cruz D, Ronco C. The RIFLE criteria and mortality in acute kidney injury: a systematic review. Kidney Int 2008; 73: 538-46.

15. Thakar CV, Christianson A, Freyberg R, Almenoff P, Render ML. Incidence and outcomes of acute kidney injury in intensive care units: a Veterans Administration study. Crit Care Med 2009; 37: 2552-8.

16. Joannidis M, Metnitz B, Bauer P, Schusterschitz N, Moreno R, Druml $\mathrm{W}$ et al. Acute kidney injury in critically ill patients classified by AKIN versus RIFLE using the SAPS 3 database. Intensive Care Med 2009; 35: 1692-702.

17. Ostermann M, Chang RW. Acute kidney injury in the intensive care unit according to RIFLE. Crit Care Med 2007; 35: 1837-43.

18. Chertow GM, Burdick E, Honour M, Bonventre JV, Bates DW. Acute kidney injury, mortality, length of stay, and costs in hospitalized patients. J Am Soc Nephrol 2005; 16: 3365-70.

19. Lassnigg A, Schmidlin D, Mouhieddine M, Bachmann LM, Druml W, Bauer $P$ et al. Minimal changes of serum creatinine predict prognosis in patients after cardiothoracic surgery: a prospective cohort study. J Am Soc Nephrol 2004; 15: 1597-605.

20. Molitoris BA, Levin A, Warnock DG, Joannidis M, Mehta RL, Kellum JA et al. Improving outcomes of acute kidney injury: report of an initiative. Nat Clin Pract Nephrol 2007; 3: 439-42.

21. Broce JC, Price LL, Liangos O, Uhlig K, Jaber BL. Hospital-acquired acute kidney injury: an analysis of nadir-to-peak serum creatinine increments stratified by baseline estimated GFR. Clin J Am Soc Nephrol 2011; 6: 1556-65.

22. Wonnacott A, Meran S, Amphlett B, Talabani B, Phillips A. Epidemiology and outcomes in community-acquired versus hospitalacquired AKI. Clin J Am Soc Nephrol 2014 ; 9: 1007-14.

23. Bagshaw SM, Laupland KB, Doig CJ, Mortis G, Fick GH, Mucenski M et al. Prognosis for long-term survival and renal recovery in critically ill patients with severe acute renal failure: a population-based study. Crit Care 2005; 9: R700-9.

24. Nash K, Hafeez A, Hou S. Hospital-acquired renal insufficiency. Am J Kidney Dis 2002; 39: 930-6.

25. Obialo CL, Okanofua EC, Tayade AS, Riley LJ. Epidemiology of de novo acute renal failure in hospitalized African Americans: comparing community-acquired versus hospital-acquired disease. Arch Intern Med 2000; 160: 1309-13.

26. Lo LJ, Go AS, Chertow GM, McCulloch CE, Fan D, Ordoñez JD et al. Dialysis-requiring acute renal failure increases the risk of progressive chronic kidney disease. Kidney Int 2009; 76: 893-9.

27. Hsu CY, Ordoñez JD, Chertow GM, Fan D, McCulloch CE, Go AS. The risk of acute renal failure in patients with chronic kidney disease. Kidney Int 2008; 74: 101-7. 
28. Stewart J, Findlay G, Smith N, Kelly K, Mason M. Adding insult to injury: a review of the care of patients who died in hospital with a primary diagnosis of acute kidney injury (acute renal failure). A report by the National Confidential Enquiry into Patient Outcome and Death, London, United Kingdom, 2009.

29. Murugan R, Karajala-Subramanyam V, Lee M, Yende S, Kong L, Carter $\mathrm{M}$ et al. Genetic and inflammatory markers of sepsis (GenIMS) investigators: acute kidney injury in non-severe pneumonia is associated with an increased immune response and lower survival. Kidney Int 2010; 77: $527-35$.

30. Schrier RW, Wang W. Acute renal failure and sepsis. N Engl J Med 2004; 351: 159-69.

31. Hou SH, Bushinsky DA, Wish JB, Cohen JJ, Harrington JT. Hospitalacquired renal insufficiency: a prospective study. Am J Med 1983; 74: 243-8.
32. Anderson RI, Schrier RW. Acute renal failure. In: Schrier RW, Gottschalk CW, eds. Diseases of the kidney. Boston: Little, Brown and Co; 1997: 1069-113.

33. Choudhury D, Ahmed Z. Drug-induced nephrotoxicity. Med Clin North Am 1997; 81: 705-17.

(C) West Indian Medical Journal 2019.

This is an article published in open access under a Creative Commons Attribution International licence (CC BY). For more information, please visit https://creativecommons.org/licenses/by/4.0/deed.en_US.

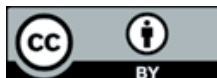

